Portland State University

PDXScholar

4-9-2021

\title{
"B-ing Flexible" : Examining Creativity in Bisexual Employees
}

Megan Jane Snoeyink

Portland State University

Follow this and additional works at: https://pdxscholar.library.pdx.edu/open_access_etds

Part of the Psychology Commons

Let us know how access to this document benefits you.

Recommended Citation

Snoeyink, Megan Jane, "'B-ing Flexible" : Examining Creativity in Bisexual Employees" (2021).

Dissertations and Theses. Paper 5676.

https://doi.org/10.15760/etd.7548

This Thesis is brought to you for free and open access. It has been accepted for inclusion in Dissertations and Theses by an authorized administrator of PDXScholar. Please contact us if we can make this document more accessible: pdxscholar@pdx.edu. 
"B-ing Flexible": Examining Creativity in Bisexual Employees

by

Megan Jane Snoeyink

A thesis submitted in partial fulfillment of the requirements for the degree of

\author{
Master of Science \\ in \\ Psychology
}

Thesis Committee:

Larry R. Martinez, Chair

Tessa L. Dover

Jason T. Newsom

Portland State University

2021 
(C) 2021 Megan Jane Snoeyink 


\begin{abstract}
Creativity is essential for organizations to remain competitive and profitable. Past evidence suggests diversity in organizations promotes creativity, however, the mechanisms through which diversity promotes creativity in the workplace are not yet understood. Diverse populations' unique experiences may promote creativity, particularly through cognitive flexibility. I investigate the potential for heightened creativity in diverse populations within the context of bisexuality. Specifically, I use the flexibility model of bisexuality to explain why bisexual employees may have greater cognitive flexibility and subsequent creativity than heterosexual employees. Additionally, I seek to understand the moderating role of supervisor support in this relationship. Participants were recruited using snowball sampling methods and Amazon's Mechanical Turk. I did not find evidence that bisexual employees have greater cognitive flexibility and subsequent creativity than heterosexual employees, nor was this relationship was moderated by supervisor support. My study contributes to the limited research surrounding the experiences of bisexual employees, presents further insight into how diversity can promote positive organizational outcomes such as creativity, and provides directions for future research.
\end{abstract}




\section{Table of Contents}

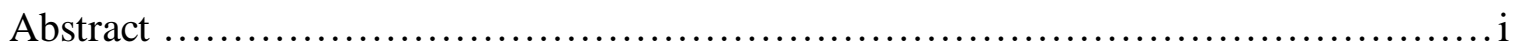

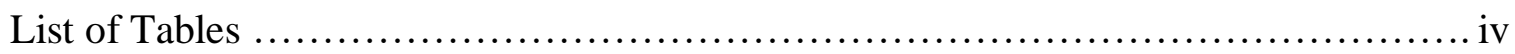

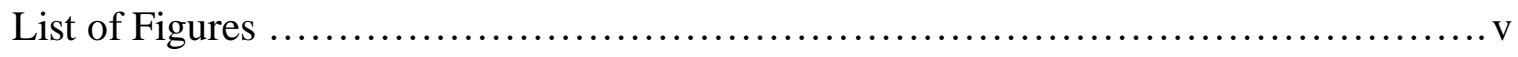

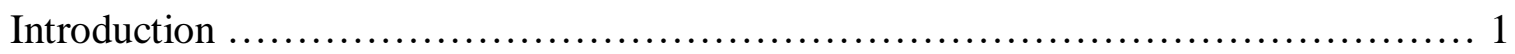

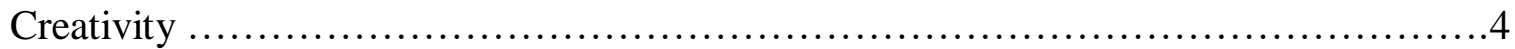

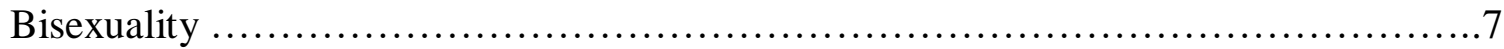

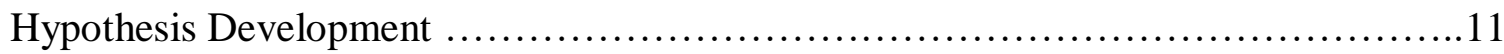

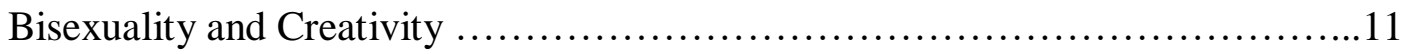

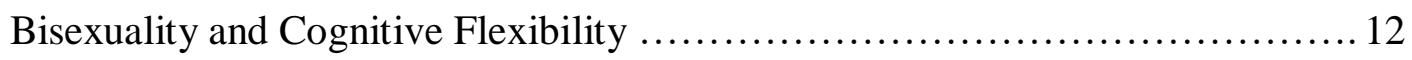

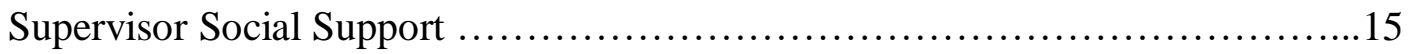

Method .......................................................................... 19

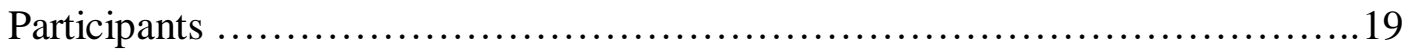

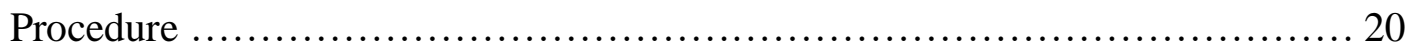

Measures .......................................................... 20

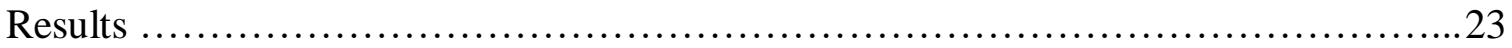

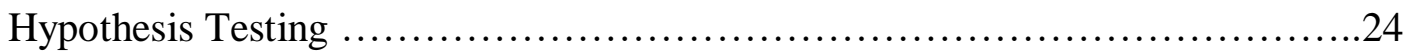

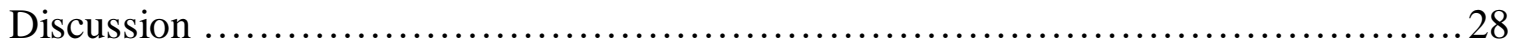

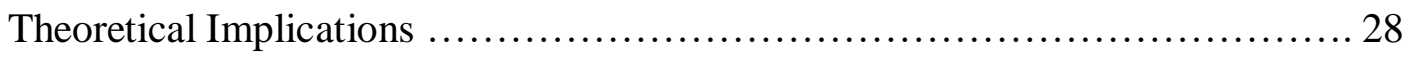

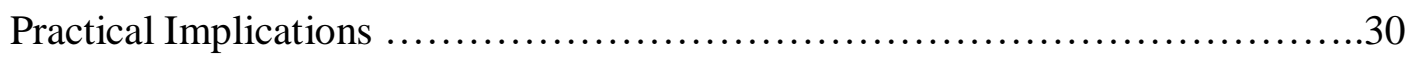

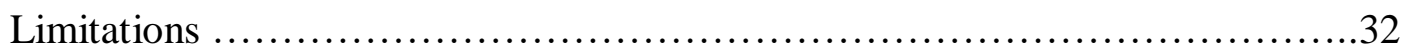

Future Directions........................................................ 34

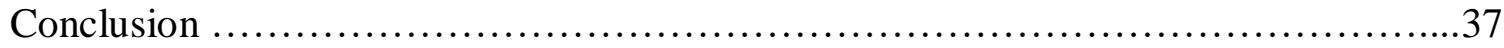

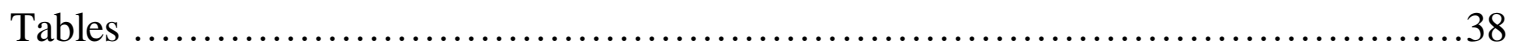

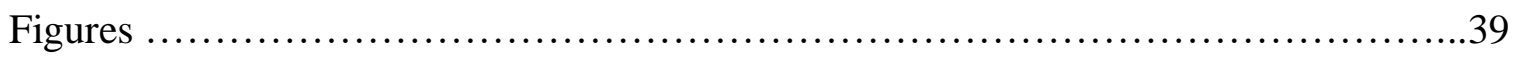

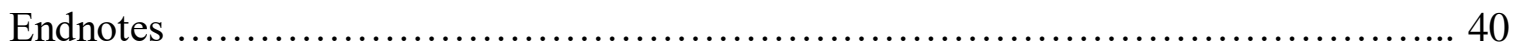




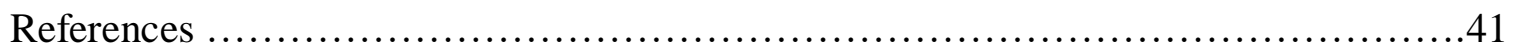

Appendix A: Survey Measures ........................................... 55

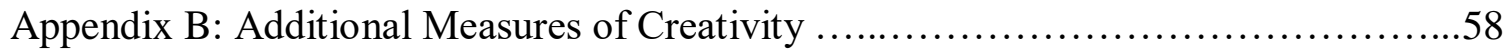

Appendix C: Final Models with Coefficients .....................................61 


\section{List of Tables}

Table 1: Means, standard deviations and correlations among focal variables........... 38 


\section{List of Figures}

Figure 1: Hypothesized relationships between variables of interest...................39 


\section{Introduction}

Creativity in organizations is essential as it allows organizations to be flexible and adapt to quickly changing global markets and economies (Shalley \& Gilson, 2004). The consequences of inflexibility are often disastrous. Organizations like Kodak and Blockbuster are now defunct because they were unable to change their approach and product offerings amid rapidly changing technology and market demands (Aaslaid, 2018). In an attempt to avoid the same fate, many organizations are searching for ways to increase creative performance among their employees and their leaders. The need for creative leaders and employees has made the recruitment of creative individuals a priority in recent years (Hess, 2019; Marr, 2019). Specifically, some organizations are selecting for creative employees by using various creativity measurements and inventories in an effort to be more innovative (McEntire \& Greene-Shortridge, 2011).

Although hiring new employees who receive high scores on creativity measures may promote creativity, it may be unnecessary as organizations likely already employ creative employees. In fact, only $31 \%$ of employees report feeling as though they are living up to their creative potential (Adobe, 2016). Thus, it may be more advantageous for organizations to encourage the remaining $69 \%$ of employees to reach their creative potential, rather than spending valuable resources on new hiring initiatives. Specifically, organizations employ diverse populations whose unique experiences encourage flexible and adaptable thinking styles that can lead to more creative outputs in the workplace. Indeed, previous research suggests that cognitive and ethnic diversity within teams and organizations predict creative performance because a variety of different perspectives 
elicits flexible thinking styles and a greater range of knowledge and experience (BassettJones, 2005; Kurtzberg, 2005). In addition, organizations may be able to promote creativity through encouraging diversity and inclusion within their employees, notably by providing their employees with supervisor support.

The goal of the present study is to further understand the relationship between diversity and employee creativity, specifically within the context of cognitive flexibility and supervisor support. To test my hypotheses, I use a sample of bisexual employees given that this is a group whose experiences have previously been overlooked both inside and outside of the workplace (Arena \& Jones, 2017; See \& Hunt, 2011), a group that is likely to be particularly creative and cognitively flexible (Ben-Zeev et al., 2012; Callis, 2014; Konik \& Crawford, 2004), and a group for which creative performance is likely dependent on supervisor support (Amabile et al., 1996; Diliello et al., 2011; Kim et al., 2010).

I contribute to the existing literature in three important ways. First, I extend the research concerned with organizational diversity and creativity. Previous research has focused on the ways in which company wide diversity or team diversity affect creative outputs and innovation (Bassett-Jones, 2005; Kurtzberg, 2005; McLeod et al., 1996). Less, if any research, has focused on how the unique experiences of a group impacts employee creative performance. By focusing on a single group's experience, I am better able to understand the mechanisms by which creativity unfolds in diverse groups. Second, I contribute to the limited research focused on the unique experiences of bisexual employees. Until recently, bisexual populations' experiences have been largely overlooked in the organizational literature by including them in larger samples with 
lesbian and gay individuals. Recent research, however, suggests that bisexual individuals have different experiences from their lesbian and gay counterparts including higher rates of hiring discrimination, worse health outcomes, and more negative perceptions about their sexual orientations (Arena \& Jones, 2017; Corrington et al., 2019). I continue to expand the workplace bisexuality research by examining how bisexual employees' experiences may also result in positive outcomes (in line with a positive psychology orientation; Seligman, 1990). Third, I further the literature on supervisor support within the context of diversity by focusing on bisexual employees. It seems that this is a population that would be especially receptive to supervisor support because of the negative outcomes they face; however, supervisor support has not been examined in bisexual employees except within a combined lesbian and gay sample (Huffman et al., 2008).

In the following sections, I first define creativity in organizational contexts and justify the method I will use to measure creativity. Second, I define bisexuality and explain why I plan to use a bisexual sample. Third, I discuss bisexuality, creativity, and the role of cognitive flexibility. Fourth, I explore these relations in the context of supervisor support and argue that bisexual individuals are better able to utilize their cognitive flexibility and thus be creative when they feel they are supported by their supervisors. Fifth, I detail the methods and analyses I use to understand these relations. Finally, I consider the implications and contributions that the results could have for the broader organizational science literature. 


\section{Creativity}

Within organizational psychology, creativity is defined as the creation of novel and useful products and ideas (Amabile et al., 1996; Shalley et al., 2004). When studying creativity in organization contexts, there are multiple ways to operationalize employee creative performance. The first approach is attempting to objectively measure creativity by judging a product for its creative qualities (Mumford et al., 2012). These types of measures include having participants describe an instance when they came up with a creative solution to a problem (Amabile, 1982), count the number of innovative solutions they have implemented in the workplace (Lu et al., 2017), or complete tasks that require a creative solution (Mumford et al., 1996). Objective measures of creativity represent an individual's ability to solve a problem in a way that is original and novel, but there are concerns about the external validity of these measures in workplace contexts. For example, the ability to complete a puzzle or ambiguous task may not extend into workplace contexts (Schoenfeldt \& Jansen, 1997). Additionally, some of these measures are not completely objective. Oftentimes, a number of raters are required to assess the quality of the responses, otherwise, the inter-rater reliability is poor (Mumford et al., 2012). The second approach involves collecting creativity ratings from others (e.g., supervisors, coworkers, customers) by using scales to assess an employee's creative performance. These ratings seem to be valid measures of creativity at work, as they represent how others perceive an individual's creativity. However, they only reflect the creative performance that the supervisor, coworker, or customer observes. That is, they may not be familiar with the entire extent of an employee's work and their creative performance (Van der Heijden, \& Nijhof, 2004). These types of ratings can also be 
difficult to collect on a large scale. The third approach involves collecting creativity ratings provided by the employee. These are typically scales that ask the participant how creative they perceive themselves to be at work. Although participants often rate themselves more positively than their supervisors (Janssen \& van der Vegt, 2011), selfreport measures correlate positively with supervisor ratings of creativity (Tierney \& Farmer, 2002). In fact, all of these methods have shown to be positively correlated (e.g., Beghetto et al., 2011; Karwowski, 2014; Tierney et al., 1999). For the purpose of this paper, I propose using self-report ratings of creativity, but I also plan to collect other measures for publication purposes.

It is important to accurately measure employee creative performance considering it drives the company's innovation, growth, and societal development (J. Zhou \& Hoever, 2014). Consequently, organizations are looking for ways to increase creative performance in their employees. Previous efforts have included selecting for creative employees by using various measurements and inventories (McEntire \& Greene-Shortridge, 2011), implementing interventions targeted at enhancing employee creativity (Basadur, 1997), and improving job design for creativity (Elsbach \& Hargadon, 2006; Q. Zhou et al., 2012). Although these strategies may be effective, they can also be costly and time consuming. A cheaper alternative may be to support and develop the employees that already work in the organization. In fact, organizations may already employ populations that are more prone to being creative including those with multiple cultural or ethnic identities, those who have lived in and experienced multiple cultures, and sexual and gender minorities employees (Ben-Zeev et al., 2012; Lu et al., 2017; Steffens et al., 2016; Tadmor et al., 2012). Since these populations are often overlooked or discriminated 
against in the workplace, their marginalized identities often result in negative outcomes (e.g., diminished employee attitudes and increased turnover intentions; Avery et al., 2007; Powers, 1996) rather than positive outcomes such as creativity. I investigate the potential for increased creativity in minority populations within the context of bisexuality. 


\section{Bisexuality}

Bisexuality first gained mainstream attention when Alfred Kinsey released the Kinsey reports in 1948. The Kinsey reports portrayed sexuality not as binary (heterosexual or homosexual) as previously thought, but instead noted that sexuality is a spectrum such that people may engage in behaviors considered both heterosexual and homosexual. Since the release of the Kinsey reports, however, researchers have struggled to define and conceptualize bisexuality. Historically, researchers believed bisexuality to be the midpoint between identifying as heterosexual and as lesbian or gay, defining bisexuality as both being attracted to and engaging in sexual behavior with both men and women (Zinik, 1985). Although these definitions were considered appropriate in their time, recently scholars have noted that traditional definitions and understandings of bisexuality do not equate to how self-identifying bisexual individuals define and experience their sexuality. For example, the belief that bisexual individuals are only attracted to cisgender men and women is often inaccurate as many bisexual individuals report being attracted to and engaging in sexual behaviors with people outside of the gender binary (Flanders et al., 2017). Additionally, researchers have identified bisexuality as both behaviors that one engages in (being in relationships, engaging in sexual activities, etc.) and as a label that one identifies with (Bauer \& Jairam, 2008). Accordingly, Flanders and colleagues (2017) define bisexuality as an 'umbrella term' that includes behaviors, a self-identity, and a binary or nonbinary identity. For the purposes of this study, I define bisexuality as a non-binary identity that is both a behavior and a part of one's self-concept. 
I examine the relationship between diversity and creativity using bisexual employees because their unique experiences within relationships allows for further examination of the predictors of creativity (discussed further below), but also because they have been excluded from previous diversity research. Bisexual individuals make up the largest and fastest growing portion of the sexual and gender minorities (Copen et al., 2016), yet research on their own unique workplace experiences is rather limited. Organizational researchers may disregard bisexual samples for a number of reasons.

First, researchers may not use bisexual samples because they do not see bisexuality as a real sexual orientation (Bradford, 2004). It is sometimes believed that those who identify as bisexual are only pretending to be attracted to multiple genders rather than admitting they are lesbian, gay, or heterosexual. In fact, both heterosexual individuals and lesbian and gay individuals may have prejudices against bisexual individuals. Heterosexual individuals often believe bisexuality is experimentation and that the individual will eventually return to being heterosexual. Conversely, lesbian and gay individuals often believe bisexuality is part of one's progression towards being gay such that the individual will eventually identify as being lesbian or gay after they feel secure enough to reveal their identity (Diamond, 2005). Consequently, past researchers may have neglected bisexual populations due to prejudicial beliefs about bisexuality or because of confusion about the bisexual experience.

Second, researchers may ignore bisexuality in their research for practical reasons. Because bisexuality is non-binary, researchers may not know how to conceptualize bisexuality or how choosing different ways to conceptualize bisexuality could impact their results. Indeed, Bauer and Jairam (2008) found that health outcomes and behaviors 
varied dramatically for bisexual individuals depending on if it was defined as a sexual identity or by two measures of behavior (sex of past-year partners, and sex of lifetime partners). Researchers may be dissuaded from studying bisexuality because of complicated definitions and interactions for which they must account.

Third, researchers may simply believe there is no difference between bisexual experiences and lesbian and gay experiences. Researchers may not see the value in collecting new data on phenomena that have already been examined with lesbian and gay employees. In fact, bisexual individuals have reported very different psychological and physical experiences from their lesbian and gay counterparts. Bisexual individuals are more likely to suffer from health problems such as higher cholesterol and lower mental and emotional well-being. Additionally, bisexual women have higher rates of breast cancer, heart disease, and obesity compared to lesbian and gay individuals (Human Rights Campaign 2016 Annual Report, 2016). Within the workplace, bisexual employees are likely to experience bias not only from heterosexual employees, but also from lesbian and gay employees. Arena and Jones (2017) found that bisexual job applicants who disclosed their sexual orientation were more likely to receive hiring penalties than gay applicants. Furthermore, Corrington and colleagues (2019) found that bisexual men may feel these negative effects more strongly such that they experience more discrimination at work and are less likely to disclose their identity.

Taken together, these reasons may explain why bisexual populations comprised less than $1 \%$ of the 223 journal articles in Psychology of Sexual Orientation and Gender Diversity (Pollitt et al., 2018). They may also explain why bisexual individuals are less likely to disclose their identities both at work and to their healthcare providers than 
lesbian and gay individuals (Arena \& Jones, 2017; Popova, 2018). Given the importance of disclosure (Ragins, 2008), it is critical that researchers aim to understand the experience of bisexual employees to reduce discrimination, bring awareness to their identity, and promote their well-being. 


\section{Hypothesis Development}

\section{Bisexuality and Creativity}

Continued research devoted to understanding the experiences of bisexual individuals will not only bring attention to a previously neglected population, but further research can also uncover strengths unique to bisexual individuals. Within organizational research, strengths of bisexual employees could be especially compelling as bisexual employees are more likely to value all aspects of diversity and inclusion compared with lesbian and gay employees (Robinson et al., 2017 as cited in Arena \& Jones, 2017), they are highly flexible in their thinking styles (Brown, 1989; Callis, 2014; Konik \& Crawford, 2004; Zinik, 1985), and they have higher self-assessments of their creativity compared with heterosexual employees (Ben-Zeev et al., 2012).

Empirical evidence supports the assumption that bisexual individuals are more creative than others. Ben-Zeez and colleagues (2012) found that bisexual women had higher self-reported creativity compared with heterosexual women. This finding highlights several important implications. First, it indicates that bisexual women may be more confident in their ability to be creative than heterosexual women. Second, it suggests bisexual women may have more creative outputs than heterosexual women as self-report scores of creativity are highly correlated with supervisor ratings and objective creative task performance (Karwowski, 2014; Tierney \& Farmer, 2002). Third, although this study did not use bisexual men, lack in gender differences in creativity suggest that this effect is prevalent across all bisexual people regardless of gender (Baer \& Kaufman, 2008). To my knowledge, this is the only research that has empirically studied the relation between bisexuality and creativity. Although they found significant results, they 
did not include any variables that may further explain why bisexual individuals are more creative than heterosexual, lesbian, or gay individuals. Based on theoretical work surrounding creativity, I believe that cognitive flexibility may further explain this relation.

\section{Bisexuality and Cognitive Flexibility}

The dual pathway to creativity model (Nijstad et al., 2010) posits that creativity is a function of both cognitive persistence and cognitive flexibility. Cognitive persistence is "the possibility of achieving creative ideas, insights, and problem solutions through hard work, the systematic and effortful exploration of possibilities, and in-depth exploration of only a few categories or perspectives" (Nijstad et al., 2010, p. 44), whereas cognitive flexibility is "a person's awareness that in any given situation there are options and alternatives available, willingness to be flexible and adapt to the situation, and selfefficacy in being flexible" (Martin \& Rubin, 1995, p. 623). The present research focuses on the cognitive flexibility pathway as it represents the ability to use a variety of perspectives and approaches to achieve creative ideas and solutions and bisexual people seem to have experiences that allow them to be cognitively flexible.

Indeed, the flexibility model of bisexuality (Zinik, 1985) proposes that bisexuality requires a greater degree of flexibility in order to successfully integrate homosexual and heterosexual identities into a multifaceted sexual orientation. In terms of behaviors, bisexual individuals participate in both heterosexual and homosexual experiences, thus having to navigate both scripts and cultural norms (Brewster et al., 2013; Zinik, 1985). In 1989, Brown termed this phenomenon 'biculturalism.' Although the term bicultural may be more appropriately used in the context of race and ethnicity, it further explains the link 
between bisexuality and creativity. By being able to consider and combine multiple perspectives to reach a creative solution, biculturalism promotes creative ideas and products that are fluent, flexible, and novel (Tadmor et al., 2012). Perhaps a better term is “borderland identity.” Recently, researchers have conceptualized bisexuality as a nonbinary sexual identity that exists in a "sexual borderland," an identity that resides somewhere within (and between) heterosexual culture and lesbian and gay cultures while simultaneously challenging monosexist expectations and norms (Brewster et al., 2013; Callis, 2014; Collins, 2004).

Another conceptualization that captures these "in between" experiences is liminality. Liminal identities were originally defined by anthropologists as temporary identities that were neither one thing or another, rather they existed in an ambiguous state that existed between two known states (Turner, 1967). In organizational contexts, liminality is commonly used in the career change literature such that employees often find themselves in a liminal state before changing careers, losing their jobs, or before changing positions within an organization (Ibarra, 2003). These liminal states are often characterized as confusing and disorienting, and they require high levels of emotional regulation and cognitive processing (Conroy \& O’Leary-Kelly, 2014). Since then, scholars have redefined liminal identities as not necessarily being temporary, but rather individuals can exist between two identities without having their own (e.g., biracial and bisexual individuals; Ibarra \& Obodaru, 2016). That is to say, bisexual individuals must navigate both heterosexual and homosexual scripts, but their relationships often exist within and between both. 
Navigating different relationship scripts presents unique relationship challenges for bisexual individuals. Considering most cultural norms and scripts are established in heterosexual contexts, all sexual minorities must create flexible approaches in navigating many aspects of living such as developing romantic relationships, maintaining family and friend relationships, and identity management (Brown, 1989). If true, lesbian and gay individuals should also have higher cognitive flexibility (and subsequently be more creative) than heterosexual individuals, however this does not seem to be the case (Konik \& Crawford, 2004; Noor et al., 2013). It seems that although gay and lesbian scripts deviate from heterosexual scripts, they are more easily defined and accepted by those who occupy them (Hamilton et al., 2019), whereas there seems to be limited consensus about how bisexual individuals should conduct themselves (Flanders et al., 2017). Additionally, once an individual engages in lesbian or gay scripts, they often stay within those scripts, not needing extended or dynamic flexibility. Bisexual scripts conceivably require more flexibility as bisexual individuals must navigate a variety of relationships and their corresponding scripts and norms. For instance, a bisexual man could date a heterosexual woman, a bisexual woman, a gay man, or a bisexual man. Additionally, bisexual individuals can also date outside the gender binary adding greater need for flexibility in creating one's own scripts. By engaging in many combinations of relationships, bisexual individuals likely have more practice being flexible and adaptable, both of which are aspects of cognitive flexibility.

There is empirical evidence supporting the flexibility model of bisexuality such that bisexual people score higher on indicators of cognitive flexibility relative to people who identify as lesbian, gay, or heterosexual (Brewster et al., 2013; Konik \& Crawford, 
2004). Conversely, there is also empirical evidence that does not support this claim (Hrehorciuc-Caragea \& White, 2017; Moore \& Norris, 2005). This discrepancy may be attributed to two aspects of study design. First, all studies used self-report measures of cognitive flexibility, which have been shown to have gender differences such that men report higher cognitive flexibility than women (Roothman et al., 2003). These measures require self-evaluation, suggesting that men perceive themselves as being more flexible and better able to adapt to various contexts. When using objective measures of cognitive flexibility, such as the Alternate Uses Test (AUT), there are no gender differences (Baer \& Kaufman, 2008). Second, the authors used different definitions and measures of cognitive flexibility including the Cognitive Flexibility Scale (CFS; Martin \& Rubin, 1995) and the Communication Flexibility Scale (CmFS; Martin \& Rubin, 1995). I address these issues by using the CFS and controlling for gender in my analyses.

In summary, being bisexual may result in the ability to draw on ideas and input across a variety of experiences that allow bisexual employees to be more creative than other employees. Therefore, I predict bisexual employees will be more creative than heterosexual employees as a result of having heightened cognitive flexibility.

Hypothesis 1. There will be an indirect effect of sexual orientation on creative performance through cognitive flexibility such that bisexual employees will score higher on creative performance than heterosexual employees due to their increased cognitive flexibility.

\section{Supervisor Social Support}

Although bisexual employees may be cognitively flexible, there are many reasons for why they may be unable to be creative in the workplace. For instance, bisexual 
employees experience discrimination and prejudice, which in turn affects their performance and creative outcomes. Minority stress theory (Meyer, 1995, 2003, 2015) posits that individuals with minority identities are more vulnerable to psychological distress (e.g., increased anxiety and depression) as a result of chronic life stressors (e.g., discrimination, prejudice) than those who belong to majority groups. Indeed, bisexual employees experience both stigma and prejudice in the workplace, and suffer negative health outcomes as a result (Corrington et al., 2019). Experiencing stigma and prejudice can also have detrimental effects on bisexual employee's job performance, as sexual minorities often use most of their resources to conceal their identities rather than using their energy and resourcefulness in their organizations, which in turn decreases their creative outputs (Powers, 1996).

Even though bisexual employees' performance may suffer from work stressors, there may be ways that organizations can improve employee health and performance. Minority stress theory also suggests that social support can lessen or buffer the effect of work stressors and lead to positive outcomes such as job satisfaction (Huffman et al., 2008). Social support in the workplace can come from all levels of the organization (House, 1981). For example, organizations can provide social support by allowing employees greater autonomy while also accommodating for different needs employees may have (Dimoff \& Kelloway, 2018). In the context of sexual minorities, organizations can provide support by creating and enacting inclusive policies that protect against discrimination (King \& Cortina, 2010). Supervisors can also provide social support by providing employees with resources (e.g., bonuses and development opportunities) and emotional support (e.g., listening to employee problems and checking in to see how they 
are doing). Supervisor support is particularly important for minority populations because they may need additional assistance as they experience the unique chronic stressors associated with having a stigmatized identity (Huffman et al., 2008).

Indeed, non-majority employees report that their work experiences are largely dependent on supervisor support. For example, racial minorities experienced more negative outcomes (i.e., absenteeism) of low supervisor support than majority employees (Avery et al., 2007). Conversely, high levels of supervisor and organizational support predicted "outness" at work (Griffith \& Hebl, 2002) and positive job attitudes (Huffman et al., 2008) for sexual minorities. It would seem that bisexual employees would benefit from supervisor support, however, there is limited supporting evidence. Although Huffman and colleagues (2008) found that supervisor support was strongly related to job attitudes among sexual minorities, their sample composition had little bisexual representation (4\%). Supervisor support is likely especially important for bisexual employees as they experience unique stressors at work as well as discrimination and bias from their heterosexual, lesbian, and gay coworkers (Arena \& Jones, 2017; Corrington et al., 2019).

While supervisor support impacts employee outcomes, it also seems that supervisor support positively impacts job outcomes. Indeed, social exchange theory posits that employees who receive social support - specifically from their supervisorsare more likely to reciprocate by supporting the organization's efforts (Eisenberger et al., 2002). Supervisor interactions with their employees are influential, particularly in the context of creativity. High quality leader-member exchange (LMX; Tierney et al., 1999), supportive leadership (Amabile et al., 2004), transformational leadership (Sosik et al., 
1998) and empowering leadership (Zhang \& Bartol, 2010) all promote creative performance in employees. Therefore, if bisexual employees perceived high levels of supervisor support they may be more creative.

Supervisor support and leadership is important for creativity and innovation among employees. Although many aspects of leadership have been studied in the context of creative performance, the effect supervisor support has on sexual minorities has not yet been fully examined. This is an important omission because of the unique positive qualities these employees may be able to utilize in work contexts, if encouraged by supportive supervisors. Therefore, I predict that bisexual employee's tendency to be more creative as a function of heightened cognitive flexibility will be strengthened by the employee's perceived levels of supervisor support.

Hypothesis 2. Supervisor support will moderate the indirect relationship between sexual orientation and creative performance such that the positive effect of cognitive flexibility on creative performance will be stronger for those employees who report higher levels of supervisor support. 


\section{Method}

\section{Participants}

In order to obtain a moderate effect size $(r=0.39)$ at an alpha of .05 , conditional indirect effect simulations suggest a sample size of at least 300 (Preacher et al., 2007). To account for attrition and inattentiveness, I recruited 400 participants using snowball sampling methods including social media, message boards, and listservs to access both heterosexual and bisexual participants. Participants were only able to participate if they were currently employed and working over 20 hours a week. Of the 400 participants recruited, only 222 completed the survey, including questions about sexual orientation, and passed the attention checks items. To obtain sufficient power in my analyses, I recruited an additional 150 participants using Amazon's Mechanical Turk (MTurk). Of these participants, 106 completed the survey, passed the attention check items, and were screened for computer generated responses by assessing their ability to respond to complex creativity tasks. Thus, the total combined sample had 328 participants. The sample contained 226 women and 102 men. Concerning sexual orientation, there were 103 bisexual participants (91 bisexual women, 12 bisexual men) and 225 heterosexual participants (135 heterosexual women, 90 heterosexual men). Participants were $75 \%$ white, 6\% African American, 11\% Hispanic/Latino, 10\% Asian, 2\% Native American, 2\% Native Hawaiian/Pacific Islander, 2\% South Asian, 1\% Middle Eastern, and 1\% identified as "Other".

Participants recruited using snowball methods were entered into a raffle drawing for a total of two prizes each valued at \$50. Participants recruited using MTurk were compensated $\$ 0.50$ for their time. 


\section{Procedure}

After consenting, participants first completed a questionnaire asking about their cognitive flexibility, perceptions of supervisor support, and self-reported creativity. Lastly, participants answered demographic questions.

\section{Measures}

All items, except demographics and creative task performance, were rated on a 7point Likert-type scale ranging from "not at all agree" (1) to "very strongly agree" (7). I computed mean scores for each of the scales before performing my analyses. All measures and items are provided in Appendix A.

\section{Cognitive Flexibility}

I asked employees to respond to a single factor, 7-item Cognitive Flexibility Scale (CFS; adapted from Martin \& Rubin, 1995). Items ask respondents to evaluate their ability to adapt to various diverse situations and consider available alternatives when making decisions. Scale reliability was low $(\alpha=.69)$. The scale included one reverse scored item "I avoid new and unusual situations". Reverse scored items may cause confusion or misunderstanding among participants (Conrad et al., 2004; Rodebaugh et al., 2007; Schriesheim et al., 1991; Swain et al., 2008), so I removed this item. The final scale had six items. An exploratory factor analysis confirmed a single factor structure with all factor loadings greater than .4 and no cross-loading (Hinkin 1995; 1998) with adequate reliability $(\alpha=.76)$. A sample item is "I am willing to listen and consider alternatives for handling a problem.”

\section{Supervisor Support}


I asked employees to respond to a single factor, 6-item scale adapted from House and Wells' (1978) supervisor support scale (Comer et al., 1997). Items ask respondents to assess social support for work-related social support provided by their supervisor. An exploratory factor analysis confirmed a single factor structure with all factor loadings greater than .4 and no cross-loading (Hinkin 1995; 1998) with adequate reliability $(\alpha=$ .97). A sample item is "My supervisor listens to my work-related problems."

\section{Creative Performance}

For the purpose of this paper, I used a self-report measure of creative performance in the workplace. Although self-report measures of creativity are correlated with many measures of workplace creativity (Karwowski, 2014; Tierney \& Farmer, 2002), I intend to also collect objective measures of creativity and supervisor or coworker ratings of creativity for publication purposes ${ }^{1}$.

I measured creative performance by asking employees to respond to a single factor, 13-item scale created by J. Zhou and George (2001) originally designed to assess supervisor ratings of employee creativity. I modified each of the items to be selfreflective. An exploratory factor analysis confirmed a single factor structure with all factor loadings greater than .4 and no cross-loading (Hinkin 1995; 1998) with adequate reliability $(\alpha=.97)$. A sample item is "I suggest new ways to achieve goals or objectives."

\section{Demographics}

I asked participants to provide demographic information including age, gender identity, race/ethnicity, educational level, and sexual orientation. For additional context, I 
also asked participants to indicate if they have been in a relationship with someone of the same gender, a different gender, or both. 


\section{Results}

Due to attrition and careless responding in the first round of recruiting using snowball sampling, a second round of recruiting took place using MTurk. In order to determine if differences existed between the MTurk sample and the snowball sampling sample, I conducted analyses using both samples. Both samples demonstrated similar results in terms of direction and effect size. Additionally, I performed $t$ tests to determine if mean differences existed between the two groups for the focal variables. There was no difference between groups for cognitive flexibility $\left(M_{M T u r k}=5.28, S D_{M T u r k}=0.99\right.$, $M_{\text {Snowball }}=5.31, S D_{\text {Snowball }}=.77, t(326)=.30, p=.77,95 \%$ CI $\left.[-0.17,0.23], d=.03\right)$ and creative performance $\left(M_{M T u r k}=4.95, S D_{M T u r k}=1.37, M_{\text {Snowball }}=4.79, S D_{\text {Snowball }}=1.08\right.$, $t(326)=-1.12, p=.26,95 \% \mathrm{CI}[-0.44,0.12], d=.13)$. There was a significant difference in ratings of supervisor support, $t(326)=-2.39, \mathrm{p}=.02,95 \%$ CI $[-0.81,-0.08], d=.30)$, such that Mturk participants $(M=5.10, S D=1.37)$ reported higher support than snowball sampling participants $(M=4.66, S D=1.58)$. Due to similar result patterns I continued my analyses with a combined sample.

Before testing my hypotheses, I examined descriptive statistics and box plots to assess for potential outliers for all the variables. There appeared to be one outlier on creative performance with low ratings of creativity (scoring 1's and 2's). There were no outliers on the other variables of interest. I conducted all analyses with and without outliers and it did not change the pattern of results, so I retained that outlier for the analyses. Descriptive statistics and correlations among variables are presented in Table 1.

I also reviewed histograms to assess normality and checked for skewness and kurtosis. All variables were approximately symmetric (skewness values less than -1 or 
greater than 1) and within the acceptable range for kurtosis (values less than -2 or greater than 2). I also inspected the data for multicollinearity, homoscedasticity, and linearity. To test for multicollinearity, I obtained the variance inflation factor (VIF) for Gender, Cognitive Flexibility, and Supervisor Support, which were all below 2, indicating low concern for multicollinearity (Gareth et al., 2013). To test for homoscedasticity, I used the Durbin-Watson test of constant variance. The Durbin-Watson value for these data was 0.99 . This is potentially problematic as the recommended value is two or greater, however, this can be misleading as it is easily influenced by large sample sizes (Ali \& Sharma; 1993; Cohen et al., 2003). I assessed the assumption of nonlinearity by looking at a scatterplot of the residuals plotted against the values of creative performance. From this plot, the data appeared to be linear and have constant variance.

\section{Hypothesis Testing}

Hypothesis 1 proposed that there would be an indirect effect of sexual orientation on creative performance through cognitive flexibility such that bisexual employees would score higher on creative performance than heterosexual employees due to their increased cognitive flexibility (see Figure 1). I examined these hypothesized mediational relationships utilizing Hayes’ PROCESS Macro (Hayes, 2018; Model 4) with percentile bootstrap confidence intervals using 10,000 samples. I entered sexual orientation as the predictor variable, creative performance as the dependent variable, and cognitive flexibility as the mediator. I also entered gender as a covariate considering the gender differences in self-report ratings of cognitive flexibility (Roothman et al., 2003). Results indicated that sexual orientation did not predict cognitive flexibility, $b=0.04 . S E=0.05$, $\beta=.00, \mathrm{p}=.41,95 \% \mathrm{CI}[-0.06,0.15]$, or creative performance, $b=.02, S E=0.06, \beta=$ 
$.02, \mathrm{p}=.75,95 \% \mathrm{CI}[-0.10,0.14]$. Cognitive flexibility did predict creative performance, $\mathrm{b}=0.87, S E=0.06, \beta=.63, \mathrm{p}<.01,95 \% \mathrm{CI}[0.75,1.0]$. Additionally, results indicated that the indirect effect of sexual orientation on creative performance through cognitive flexibility was not significant, $b=0.04, S E=0.05, \beta=.03,95 \%$ CI $[-0.06,0.13]$.

Hypothesis 2 stated that supervisor support would moderate the indirect relationship between sexual orientation and creative performance such that the positive effect of cognitive flexibility on creative performance would be stronger for those employees who reported higher levels of supervisor support. I examined these hypothesized relationships utilizing Hayes’ PROCESS Macro (Hayes, 2018; Model 14) with percentile bootstrap confidence intervals using 10,000 samples. I entered sexual orientation as the predictor variable, creative performance as the dependent variable, cognitive flexibility as the mediator, and supervisor support as the moderator (on the b path). I also entered gender as a covariate again. Results indicated that sexual orientation did not predict cognitive flexibility, $b=0.04, S E=0.05, \beta=.00, \mathrm{p}=.41,95 \% \mathrm{CI}[-0.06$, 0.15], or creative performance, $b=0.02, S E=0.06, \beta=.02, \mathrm{p}=.67,95 \%$ CI $[-0.09$, 0.14]. Cognitive flexibility did predict creative performance, $b=0.93 S E=0.20, \beta=.63$, $\mathrm{p}<.01,95 \%$ CI $[0.54,1.32]$. Additionally, results indicated that the moderated mediation effect of supervisor support was not significant, $b=0.00, S E=0.00, \beta=.00,95 \% \mathrm{CI}=[-$ 0.01, 0.01]. The model is presented in Appendix C.

\section{Exploratory Analyses}

Because the literature suggests there are gender differences in self-reports of cognitive flexibility, such that men report having higher cognitive flexibility (Baer \& Kaufman, 2008; Roothman et al., 2003), I assessed mean differences among focal 
variables by gender using an independent samples ttest as part of exploratory analyses. There was a significant difference in ratings of creative performance, $t(326)=3.70, \mathrm{p}=$ $.00,95 \%$ CI $[0.25,0.80], d=.46)$, such that men $(M=5.2, S D=1.06)$ reported higher creative performance than women $(M=4.67, S D=1.22)$. There was also a significant difference in ratings of cognitive flexibility, $t(326)=2.87, \mathrm{p}=.00,95 \% \mathrm{CI}[0.10,0.49], d$ $=.36)$, such that men $(M=5.51, S D=0.82)$ reported higher cognitive flexibility than women $(M=5.21, S D=0.86)$. Finally, there was a significant difference in ratings of supervisor support, $t(326)=2.76, \mathrm{p}=.01,95 \% \mathrm{CI}[0.17,0.85], d=.34)$, such that men $(M=5.17, S D=1.32)$ reported higher supervisor support than women $(M=4.67, S D=$ 1.61). In sum, men scored significantly higher than women on all focal variables.

Since there were significant gender differences across all focal variables, I substituted gender as the independent variable when testing my hypotheses. In the case of Hypothesis 1, I entered gender as the predictor variable, creative performance as the dependent variable, and cognitive flexibility as the mediator. Results indicated that gender did predict cognitive flexibility, $b=-0.19, S E=0.08, \beta=-.14, \mathrm{p}<.05,95 \% \mathrm{CI}[-$ $0.34,-.04]$, and creative performance, $b=-0.20, S E=0.08, \beta=-.19, \mathrm{p}<.05,95 \%$ CI $[-$ $0.36,-0.04]$, such that men reported higher cognitive flexibility and creativity than women did. Cognitive flexibility did predict creative performance, $\mathrm{b}=0.88 S E=0.06, \beta$ $=.63, \mathrm{p}<.01,95 \% \mathrm{CI}[0.75,1.0]$. Additionally, results indicated that the indirect effect of gender on creative performance through cognitive flexibility was significant, $b=-0.17$, $S E=0.07, \beta=-.13,95 \%$ CI $[-0.32,-0.04]$. There was an indirect effect of gender on creative performance through cognitive flexibility such that men scored higher on creative performance than women due to their higher reported cognitive flexibility. 
Similarly, for Hypothesis 2, I entered gender as the predictor variable, creative performance as the dependent variable, cognitive flexibility as the mediator, and supervisor support as the moderator (on the b path). Results indicated that gender did predict cognitive flexibility, $b=-0.19, S E=0.08, \beta=-.14, \mathrm{p}<.05,95 \%$ CI $[-0.34,-.04]$, and creative performance, $b=-0.20, S E=0.08, \beta=-.19, \mathrm{p}<.05,95 \%$ CI $[-0.34,-0.01]$, such that men reported higher cognitive flexibility and creativity than women did. Cognitive flexibility did predict creative performance, $\mathrm{b}=0.93 S E=0.20, \beta=.63$, $\mathrm{p}$ $<.01,95 \%$ CI $[0.54,1.33]$. Additionally, results indicated that the moderated mediation effect of supervisor support was not significant, $b=0.003, S E=0.01, \beta=.01,95 \% \mathrm{CI}=$ $[-0.01,0.02]$. The model is presented in Appendix C. 


\section{Discussion}

The purpose of this study was to further understand the relation between diversity and creativity specifically within the context of bisexual employees. I expected that bisexual employees would be more creative as a result of navigating a variety of relationships and interpersonal scripts and having high cognitive flexibility. I also expected that their creativity would be dependent on their perceived supervisor support as research suggests that bisexual individuals experience discrimination at work (Arena \& Jones, 2017). Results suggested that bisexual individuals did not have higher selfreported creativity through cognitive flexibility, nor was this effect moderated by supervisor support. In the following sections, I discuss the theoretical and practical implications of these results as well as limitations and future research directions.

\section{Theoretical Implications}

My results contribute to the organizational creativity literature by continuing the limited research devoted to understanding the relationship between creative performance and diversity. Past research has demonstrated that diversity promotes creative performance in teams and within organizations (Bassett-Jones, 2005; Kurtzberg, 2005; McLeod et al., 1996), however, it is unclear why diversity leads to creativity in organizations. I suspect that the diverse groups have a wide array of experiences that allow them to be more flexible and subsequently more creative than those who have less diverse life experiences. Although this relationship was not found when comparing bisexual employees and heterosexual employees, to my knowledge, I am one of the first to look at how experiences related to a diverse identity promote creativity in the workplace. Additionally, there is limited creativity research that has focused on creativity 
differences among sexual orientation minorities, and there is only one study that has examined the difference of self-reported creativity among bisexual and heterosexual women (Ben-Zeez et al., 2012). I extend this research by including men in my analyses, however I did not replicate their finding that bisexual individuals were more creative than heterosexual individuals.

I did, however, find that there were significant gender differences between men and women's self-reported creativity and cognitive flexibility. Other authors have found gender differences in self-reported cognitive flexibility (Carter, 1985; Roothman et al., 2003) and creativity (Karwowski, 2011). Conversely, many studies have found that there are no significant differences between men and women in terms of creativity, although the majority of these studies did not rely on self-reported creativity (Baer \& Kaufman, 2008; Chan, 2005; Kogan, 1974; Mednick, 1962; Mednick \& Mednick, 1967). I may have found gender differences because men and women assess their abilities differently, specifically when a task or skill is gendered or related to gender roles (Stolzfus et al., 2011). Indeed, women tend to underestimate their ability on more masculine tasks (Beyer, 1998). Regarding creative self-reports, men and women tend to assess their creativity consistent with traditional gender stereotypes such that men report being more creative in areas related to science and sports and women report being more creative in areas related social-communication and visual-artistic (Kaufman, 2006). Furthermore, these self-ratings are not always congruent with performance. For example, men were categorized by higher creative self-efficacy, but they tended to overestimate their abilities when compared with creative performance (Karwowski, 2011). By not accounting for the gendered perceptions of creativity and self-report bias, I may have inaccurately found 
gender differences in creativity. Similarly, regarding cognitive flexibility, men perceive themselves to display high flexibility in accordance with gender stereotypes that men should be competent at problem solving (Roothman et al., 2003), however when using objective measures of cognitive flexibility, such as the Alternate Uses Test (AUT), there are no gender differences (Baer \& Kaufman, 2008). I anticipated these gender differences and controlled for gender in my analyses.

This study also continues the research that has been done on bisexual individuals, and bisexual employees in particular. Bisexual employees have been found to experience increased discrimination due to their sexual orientation leading to a myriad of negative health outcomes such as psychological distress, higher cholesterol, and lower mental and emotional well-being (Arena \& Jones, 2017; Corrington et al., 2019). My research presents another avenue of research concerning the bisexual population in being the first to examine bisexual employees in accordance with principles of positive psychology by examining ways in which bisexual employees are particularly skilled and useful in

organizational contexts (Seligman, 1990). Although research on the negative outcomes of being bisexual are important and deserve further research attention, research on the positive outcomes of having this identity are also important and avoid adopting a detriment mindset with respect to this population. Having a positive self-view and selfcompassion results in a number of positive life and health outcomes such as emotional regulation, healthy eating, and exercise (Sirois et al., 2014; Terry \& Leary, 2011).

\section{Practical Implications}

From an organizational perspective, my research provides practical insights for diversity management. Differences in reports of cognitive flexibility and creativity 
among genders suggest that organizations should continue to develop and support marginalized individuals who may have low self-efficacy. Low self-efficacy may lead to decreased work and task effort, persistence, expressed interest, and creativity performance (Gist, 1987; Gardner \& Pierce, 1998). By working to boost self-perceptions and self-esteem among employees, organizations can improve their performance (Parker, 1998).

Although I did not find a significant effect of sexual orientation on creativity, there was a positive relationship between cognitive flexibility and creativity (Martin \& Rubin, 1995; Nijstad et al., 2010). Organizations might consider this relationship by encouraging employees to think about problems from multiple perspectives and coaching employees to improve their cognitive flexibility through mindfulness (Moore \& Malinowski, 2009). Organizations could also select for employees that have high cognitive flexibility for jobs requiring creativity outputs. Considering the possible gender differences in self-report measures, organizations should utilize validated cognitive flexibility tasks such as the AUT to avoid adverse impact. Similarly, organizations could use creative performance and creativity assessments as a selection tool. Indeed, Kaufman (2017) suggests that creativity assessments could be used in assessments of ability and achievement to be more equitable for diverse employees and reduce adverse impact for minority populations.

Furthermore, I did not find a significant effect for supervisor support among bisexual employees, however, there was a positive relationship between reports of supervisor support and reports of creative performance. Organizations should continue to emphasize the importance of supervisor support for employee performance and 
creativity. Supervisor interactions with their employees are influential, particularly in the context of creativity. High quality leader-member exchange (LMX; Tierney et al., 1999), supportive leadership (Amabile et al., 2004), transformational leadership (Sosik et al., 1998) and empowering leadership (Zhang \& Bartol, 2010) all promote creative performance in employees. Moreover, as the workforce becomes increasingly diverse (Toossi, 2015), it is crucial for organizations to form policies that aim to reduce prejudice and that are diversity-affirming to promote employee performance. Additionally, organizations must train their supervisors to be supportive. Many minority identities are invisible, and some employees may not disclose their identities (Jones \& King, 2014). Consequently, supervisors should be trained to give all of their employees adequate social support. Supervisors should also be coached on how to support their employees, specifically employees from marginalized populations (Griffith \& Hebl, 2002).

\section{Limitations}

There were limitations to this study that may have restricted my ability to find evidence that non-majority employees, specifically bisexual employees, are able to draw on a wide range of experiences to be more flexible and adaptive in their thinking styles to form more creative ideas. First, self-report measures of creativity may not accurately represent an individual's actual creativity, however, they can represent an individuals' belief in their ability to be creative. Future studies should use objective measures and external data sources, such as supervisor ratings, to better understand this relationship. Utilizing one-time point using cross-sectional data limits the ability to make assumptions about causation. Since this study is the first to examine creativity in bisexual employees, cross-sectional data allows an initial glimpse at the relationship. 
Next, the use of self-report measures may have also been prone to gender bias such that men rated themselves more favorably than women. Indeed, men reported themselves to be more cognitively flexible and more creative than women, however, there was a very low number of bisexual men. This is not surprising as bisexual men are more likely to experience stigma and discrimination associated with their sexual orientation making it more likely that they will not publicly disclose their orientation (Corrington et al., 2019; Eliason, 1997). Future research should make concerted efforts to recruit from this population.

Additionally, this study's measurement of focal constructs may have restricted my ability to find support for my hypotheses. By using a self-report scale of creativity, I may have compromised construct validity. Specifically, I limited my understanding of creativity to include self-reports of creativity at work which may have been too constraining. For example, many participants reported difficulty in accurately responding to the measure as they work in jobs that do not allow for creative expression. Future research should examine test criterion validity by comparing self-report scores with other measures of creativity such as peer ratings, creativity outside of work, or performance on a creative task. Similarly, my measure of cognitive flexibility may have had low construct validity such that self-reports may not reflect one's actual ability to be flexible in their thinking styles. Furthermore, the reliability for this scale was adequate $(\alpha=.76)$, but could be improved by using different items and measures. For these reasons using additional measures of cognitive flexibility in future research such as peer ratings or tasks designed to assess flexibility (e.g., AUT) may improve construct validity and improve my ability to find supporting evidence. 
Finally, a limitation of this research is that participants were not randomly selected. By targeting message boards and listservs aimed at bisexual individuals, I only included bisexual individuals who use the Internet and are members of online LGBTQ+ communities. This may limit generalizability and may affect the strength of results by restricting the sample. This was the best method because the number of bisexual employees needed to for an accurate statistical analysis could likely not be obtained from recruiting within one organization. Additionally, since employees were drawn across a number of industries and contexts, definitions of creativity might have varied. A sample limited to one organization may have shown different results because the criteria for creative performance is more standardized.

\section{Future Directions}

My findings have clear implications for future research. First, researchers should continue to explore the relation between diversity and creativity. I did not find evidence supporting my hypotheses, but perhaps different predictors related to diversity might function better such as measuring past diverse experiences. For example, future research could account for individual's contact with other types of people and situations, how many places an individual has lived in, and the number of social identities one has (Lu et al., 2017; Steffens et al., 2016; Tadmor et al., 2012). Additionally, although my study utilizes the dual pathway to creativity model (Nijstad et al., 2010), I only focused on the cognitive flexibility pathway. Future research should continue to use this model in order to understand how cognitive persistence relates to diversity and creativity. Perhaps having a diverse identity and enduring the negative experiences associated with that identity results in increased resilience and persistence that then leads to creativity. 
Furthermore, the impact of additional moderators and mediators such as authenticity, outness at work, and diversity climate should be explored.

Second, researchers should continue to explore the positive outcomes of having a bicultural identity possibly using different conceptualizations of these identities. In this project, bisexuality was measured by having individuals self-identify with a sexual orientation. This measurement of sexual orientation may not have predicted cognitive flexibility if the identity did not match the individual's experience. For example, one may identify as bisexual but their dating experiences have been limited in number of partners or gender of partners. Future research might compare how different conceptualizations of bicultural identities explain the positive impacts of having a non-binary identity such as improved mental health and increased life satisfaction (David et al., 2009). Additionally, heightened cognitive flexibility has been identified as a mental health promoter for bicultural individuals and is negatively associated with lower depression symptoms and psychological distress (Palm \& Follette, 2011). Furthermore, Ben-Zeez and colleagues (2012) suggested that bisexual individuals' heightened sense of creativity and flexibility acts as a source of resilience in the face of societal stigma. Researchers should continue efforts to understand what other positive outcomes exist when diversity is managed correctly.

Finally, further research could investigate new ways for organizations to promote and support diverse employee identities. Minority employees may attempt to hide their identity and assimilate to the majority group (Jones \& King, 2014); however, if diverse experiences promote creative performance, suppressing one's identity could be harmful to the individual and the organization. Instead, organizations could increase creative 
performance by encouraging employees to draw on their diverse experiences in their daily tasks. For example, Lu and colleagues (2017) found that participants who were asked to think about an experience they had when dating an individual outside of their own culture were more creative than those who were asked to think about an experience they had when dating an individual within their own culture. In the same way, experimental research could randomly assign bisexual employees to conditions where they are instructed to either think about an experience related to being bisexual or think about an unrelated experience. If bisexual employees who thought about their experiences with their identity were more creative than those who did not think about their identity, it would suggest that organizations should encourage acceptance and conversation around diverse identities. 


\section{Conclusion}

Organizations value creativity and are pursuing new ways to enhance employee creativity (Kurtzberg, 2005; McLeod et al., 1996). Diversity in organizations is suggested to promote creativity (Bassett-Jones, 2005), however the mechanisms that explain this link are not well understood. A possible explanation is that non-majority employees are able to draw on a wide range of experiences to be more flexible and adaptive in their thinking styles to form more creative ideas. Although I did not find significant results in the context of bisexual employees, this study confirms the importance of cognitive flexibility in predicting creative performance. Organizations should encourage all of their employees to consider multiple perspectives when creative problem solving as well as provide them with adequate supervisor support. 


\section{Tables}

Table 1

Means, standard deviations, and correlations

\begin{tabular}{lcccccc}
\hline Variable & $M$ & $S D$ & 1 & 2 & 3 & 4 \\
\hline 1. Gender & 0.76 & 0.62 & & & \\
2. Orientation & 0.63 & 0.93 & $.33^{* *}$ & & & \\
$\begin{array}{l}\text { 3. Cognitive } \\
\text { Flexibility }\end{array}$ & 5.30 & 0.86 & $-.14^{*}$ & -.00 & & \\
$\begin{array}{l}\text { 4. Supervisor } \\
\text { Support }\end{array}$ & 4.79 & 1.57 & $-.19^{* *}$ & -.10 & $.27^{* *}$ & \\
$\begin{array}{l}\text { 5. Creative } \\
\text { Performance }\end{array}$ & 4.84 & 1.22 & $-.19^{* *}$ & -.02 & $.63^{* *}$ & $.26^{* *}$ \\
& & & & & & \\
\hline
\end{tabular}

Note. $M$ and $S D$ are used to represent mean and standard deviation, respectively.

$*$ indicates $p<.05 . * *$ indicates $p<.01$. 


\section{Figures}

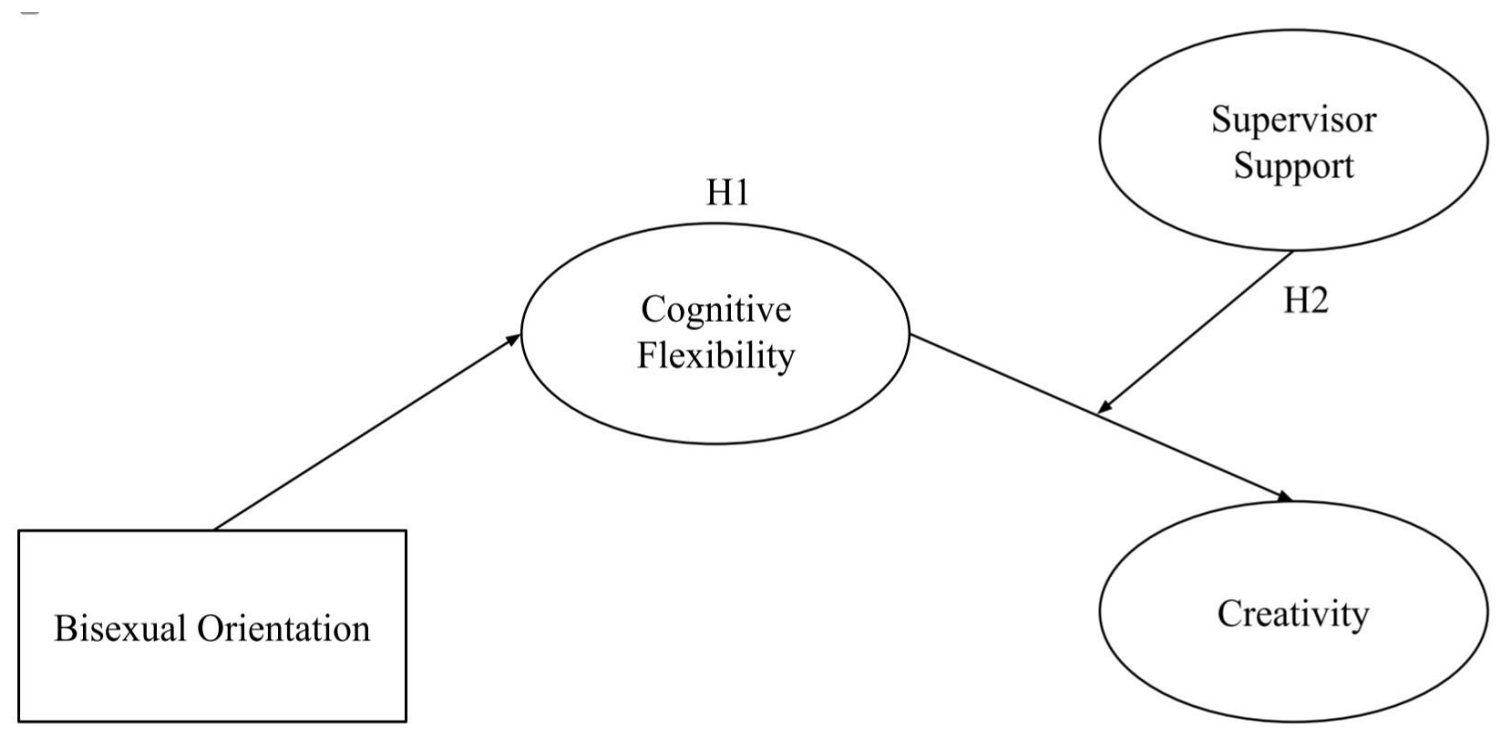

Figure 1. Hypothesized Moderated Mediation Model. 


\section{Endnotes}

${ }^{1}$ See Appendix B for additional measures. 


\section{References}

Aaslaid, K. (2018, November 22). 50 Examples of Corporations That Failed to Innovate. Valuer. https://valuer.ai/blog/50-examples-of-corporations-that-failed-toinnovate-and-missed-their-chance/

Adobe. (2016). State of Create: 2016.

https://www.adobe.com/content/dam/acom/en/max/pdfs/AdobeStateofCreate_201 6_Report_Final.pdf

Ali, M. M., \& Sharma, S. C. (1993). Robustness to nonnormality of the Durbin-Watson test for autocorrelation. Journal of Econometrics, 57(1-3), 117-136.

Amabile, T. M. (1982). Social psychology of creativity: A consensual assessment technique. Journal of Personality and Social Psychology, 43(5), 997.

Amabile, T. M., Conti, R., Coon, H., Lazenby, J., \& Herron, M. (1996). Assessing the work environment for creativity. Academy of Management Journal, 39(5), 11541184.

Amabile, T. M., Schatzel, E. A., Moneta, G. B., \& Kramer, S. J. (2004). Leader behaviors and the work environment for creativity: Perceived leader support. The Leadership Quarterly, 15(1), 5-32.

Arena, D. F., \& Jones, K. P. (2017). To "B" or not to "B": Assessing the disclosure dilemma of bisexual individuals at work. Journal of Vocational Behavior, 103, 86-98.

Avery, D. R., McKay, P. F., Wilson, D. C., \& Tonidandel, S. (2007). Unequal attendance: The relationships between race, organizational diversity cues, and absenteeism. Personnel Psychology, 60(4), 875-902. 
Baer, J., \& Kaufman, J. C. (2008). Gender differences in creativity. The Journal of Creative Behavior, 42(2), 75-105.

Basadur, M. (1997). Organizational development interventions for enhancing creativity in the workplace. The Journal of Creative Behavior, 31(1), 59-72.

Bassett-Jones, N. (2005). The paradox of diversity management, creativity and innovation. Creativity and Innovation Management, 14(2), 169-175.

Bauer, G. R., \& Jairam, J. A. (2008). Are lesbians really women who have sex with women (WSW)? Methodological concerns in measuring sexual orientation in health research. Women \& Health, 48(4), 383-408.

Beghetto, R. A., Kaufman, J. C., \& Baxter, J. (2011). Answering the unexpected questions: Exploring the relationship between students' creative self-efficacy and teacher ratings of creativity. Psychology of Aesthetics, Creativity, and the Arts, 5(4), 342 .

Ben-Zeev, A., Dennehy, T. C., \& Kaufman, J. C. (2012). Blurring boundaries: Bisexual versus lesbian and heterosexual women's self-assessed creativity. Journal of Bisexuality, 12(3), 347-359.

Beyer, S. (1998). Gender differences in self-perception and negative recall biases. Sex Roles, 38(1-2), 103-133.

Bradford, M. (2004). The bisexual experience. Journal of Bisexuality, 4(1-2), 7-23. https://doi.org/10.1300/J159v04n01_02

Brewster, M. E., Moradi, B., DeBlaere, C., \& Velez, B. L. (2013). Navigating the borderlands: The roles of minority stressors, bicultural self-efficacy, and cognitive flexibility in the mental health of bisexual individuals. Journal of Counseling 
Psychology, 60(4), 543.

Brown, L. S. (1989). New voices, new visions: Toward a lesbian/gay paradigm for psychology. Psychology of Women Quarterly, 13(4), 445-458.

Callis, A. S. (2014). Bisexual, pansexual, queer: Non-binary identities and the sexual borderlands. Sexualities, 17(1-2), 63-80.

Carter, D. B. (1985). Relationships between cognitive flexibility and sex-role orientation in young adults. Psychological Reports, 57(3), 763-766.

Chan, D. W. (2005). Self-perceived creativity, family hardiness, and emotional intelligence of Chinese gifted students in Hong Kong. Journal of Secondary Gifted Education, 16, 47-56.

Charyton, C. (2007). What is the relationship between sexual orientation, bisexuality and creativity? Journal of Bisexuality, 6(4), 49-69.

Cohen, J., Cohen, P., West, S. G., \& Aiken, L. S. (2003). Applied multiple regression/correlation for the behavioral sciences. Mahwah, NJ: Lawrence Erlbaum.

Collins, J. F. (2004). The intersection of race and bisexuality: A critical overview of the literature and past, present, and future directions of the "borderlands." Journal of Bisexuality, 4(1-2), 99-116.

Comer, J. M., Deeter-Schmelz, D. R., \& Ramsey, R. P. (1997). Methods in sales research: Considering sources and types of social support: A psychometric evaluation of the House and Wells (1978) Instrument. Journal of Personal Selling \& Sales Management, 17(1), 49-61.

Conrad, K. J., Wright, B. D., McKnight, P., McFall, M., Fontana, A., \& Rosenheck, R. 
(2004). Comparing traditional and Rasch analyses of the Mississippi PTSD Scale: Revealing limitations of reverse-scored items. Journal of Applied Measurement, 5(1), 15-30.

Conroy, S. A., \& O’Leary-Kelly, A. M. (2014). Letting go and moving on: Work-related identity loss and recovery. Academy of Management Review, 39(1), 67-87.

Copen, C. E., Chandra, A., \& Febo-Vazquez, I. (2016). Sexual behavior, sexual attraction, and sexual orientation among adults aged 18-44 in the United States: Data from the 2011-2013 National Survey of Family Growth. National Health Statistics Reports, 88, 1-14.

Corrington, A., Nittrouer, C. L., Trump-Steele, R. C., \& Hebl, M. (2019). Letting him B: A study on the intersection of gender and sexual orientation in the workplace. Journal of Vocational Behavior, 113, 129-142.

David, E. J. R., Okazaki, S., \& Saw, A. (2009). Bicultural self-efficacy among college students: Initial scale development and mental health correlates. Journal of Counseling Psychology, 56(2), 211.

Diamond, L. M. (2005). 'I'm straight, but I kissed a girl': The trouble with American media representations of female-female sexuality. Feminism \& Psychology, 15(1), $104-110$.

Diliello, T. C., Houghton, J. D., \& Dawley, D. (2011). Narrowing the creativity gap: The moderating effects of perceived support for creativity. The Journal of Psychology, 145(3), 151-172.

Dimoff, J. K., \& Kelloway, E. K. (2018). Leaders as resources: How managers and supervisors can socially support employees toward better mental health and well- 
being. In Leading to occupational health and safety: How leadership behaviours impact organizational safety and well-being. Hoboken, NJ, US: Wiley Blackwell. Eisenberger, R., Stinglhamber, F., Vandenberghe, C., Sucharski, I. L., \& Rhoades, L. (2002). Perceived supervisor support: Contributions to perceived organizational support and employee retention. Journal of Applied Psychology, 87(3), 565-573.

Eliason, M. J. (1997). The prevalence and nature of biphobia in heterosexual undergraduate students. Archives of Sexual Behavior, 26, 317-326.

Elsbach, K. D., \& Hargadon, A. B. (2006). Enhancing creativity through "mindless" work: A framework of workday design. Organization Science, 17(4), 470-483.

Flanders, C. E., LeBreton, M. E., Robinson, M., Bian, J., \& Caravaca-Morera, J. A. (2017). Defining bisexuality: Young bisexual and pansexual people's voices. Journal of Bisexuality, 17(1), 39-57.

Gardner, D. G., \& Pierce, J. L. (1998). Self-esteem and self-efficacy within the organizational context: An empirical examination. Group \& Organization Management, 23(1), 48-70.

Gareth, J., Daniela, W., Trevor, H., \& Robert, T. (2013). An introduction to statistical learning: with applications in R. New York, NY, US: Springer.

Gist, M. E. (1987). Self-efficacy: Implications for organizational behavior and human resource management. Academy of Management Review, 12(3), 472-485.

Griffith, K. H., \& Hebl, M. R. (2002). The disclosure dilemma for gay men and lesbians: “Coming out” at work. Journal of Applied Psychology, 87(6), 1191-1199.

Guilford, J. (1967). The nature of human intelligence. New York, NY, US: McGraw-Hill. Hamilton, K. M., Park, L. S., Carsey, T. A., \& Martinez, L. R. (2019). 'Lez be honest": 
Gender expression impacts workplace disclosure decisions. Journal of Lesbian Studies, 23(2), 144-168.

Hayes, A. F. (2018). Introduction to mediation, moderation, and conditional process analysis second edition: A regression-based approach. New York, New York, US: The Guilford Press.

Hess, A. (2019, January 8). This is the most in-demand skill of 2019, according to LinkedIn. CNBC. https://www.cnbc.com/2019/01/07/the-most-in-demand-skillof-2019-according-to-linkedin.html

Hinkin, T. R. (1995). A review of scale development practices in the study of organizations. Journal of Management, 21, 967-988.

Hinkin, T. R. (1998). A brief tutorial on the development of measures for use in survey questionnaires. Organizational Research Methods, 1, $104-121$.

House, J. (1981). Work stress and social support. Boston, MA: Addison-Wesley.

Hrehorciuc-Caragea, A., \& White, L. T. (2017). An investigation of the relationship between psychological flexibility and bisexuality. Journal of Bisexuality, 17(4), $473-486$.

Huffman, A. H., Watrous-Rodriguez, K. M., \& King, E. B. (2008). Supporting a diverse workforce: What type of support is most meaningful for lesbian and gay employees? Human Resource Management, 47(2), 237-253.

Human Rights Campaign 2016 Annual Report. (2016). Human Rights Campaign. https://issuu.com/humanrightscampaign/docs/hrc-annualreport-2015

Ibarra, H. (2003). Working identity: Unconventional strategies for reinventing Your Career. Bostan, MA, US: Harvard Business School Press. 
Ibarra, Herminia, \& Obodaru, O. (2016). Betwixt and between identities: Liminal experience in contemporary careers. Research in Organizational Behavior, 36, $47-64$.

Janssen, O., \& van der Vegt, G. S. (2011). Positivity bias in employees' self-ratings of performance relative to supervisor ratings: The roles of performance type, performance-approach goal orientation, and perceived influence. European Journal of Work and Organizational Psychology, 20(4), 524-552.

Jenkins, R., \& Elliott, P. (2004). Stressors, burnout and social support: Nurses in acute mental health settings. Journal of Advanced Nursing, 48(6), 622-631.

Jones, K. P., \& King, E. B. (2014). Managing concealable stigmas at work: A review and multilevel model. Journal of Management, 40(5), 1466-1494.

Karwowski, M. (2014). Creative mindsets: Measurement, correlates, consequences. Psychology of Aesthetics, Creativity, and the Arts, 8(1), 62.

Kaufman, J. C. (2006). Self-reported differences in creativity by ethnicity and gender. Applied Cognitive Psychology, 20(8), 1065-1082.

Kaufman, J. C. (2017). Looking forward: The potential of creativity for social justice and equity (and other exciting outcomes). The Journal of Creative Behavior, 51(4), 305-307.

Kim, T.-Y., Hon, A. H., \& Lee, D.-R. (2010). Proactive personality and employee creativity: The effects of job creativity requirement and supervisor support for creativity. Creativity Research Journal, 22(1), 37-45.

King, E. B., \& Cortina, J. M. (2010). The social and economic imperative of lesbian, gay, bisexual, and transgendered supportive organizational policies. Industrial and 
Organizational Psychology, 3(1), 69-78.

Konik, J., \& Crawford, M. (2004). Exploring normative creativity: Testing the relationship between cognitive flexibility and sexual identity. Sex Roles, 51(3-4), 249-253.

Kurtzberg, T. R. (2005). Feeling creative, being creative: An empirical study of diversity and creativity in teams. Creativity Research Journal, 17(1), 51-65.

Lu, J. G., Hafenbrack, A. C., Eastwick, P. W., Wang, D. J., Maddux, W. W., \& Galinsky, A. D. (2017). "Going out" of the box: Close intercultural friendships and romantic relationships spark creativity, workplace innovation, and entrepreneurship. Journal of Applied Psychology, 102(7), 1091-1108.

Marr, B. (2019, October 28). The 10+ most important job skills every company will be looking for in 2020. Forbes. https://www.forbes.com/sites/bernardmarr/2019/10/28/the-10-most-importantjob-skills-every-company-will-be-looking-for-in-2020/\#3e936edd67b6

Martin, M. M., \& Rubin, R. B. (1995). A new measure of cognitive flexibility. Psychological Reports, 76(2), 623-626.

McEntire, L. E., \& Greene-Shortridge, T. M. (2011). Recruiting and selecting leaders for innovation: How to find the right leader. Advances in Developing Human Resources, 13(3), 266-278.

McLeod, P. L., Lobel, S. A., \& Cox Jr, T. H. (1996). Ethnic diversity and creativity in small groups. Small Group Research, 27(2), 248-264.

Mednick, S. A. (1962). The associative basis of the creative process. Psychological Review, 69, 220-227. 
Mednick, S. A., \& Mednick, M. T. (1967). Remote Associates Test examiner's manual. Boston: Houghton Mifflin.

Meyer, I. H. (1995). Minority stress and mental health in gay men. Journal of Health Sciences and Social Behavior, 36, 38-56.

Meyer, I. H. (2003). Prejudice, social stress, and mental health in lesbian, gay, and bisexual populations: Conceptual issues and research evidence. Psychological Bulletin, 129(5), 674-697.

Meyer, I. H. (2015). Resilience in the study of minority stress and health of sexual and gender minorities. Psychology of Sexual Orientation and Gender Diversity, 2(3), 209-213.

Moore, A., \& Malinowski, P. (2009). Meditation, mindfulness and cognitive flexibility. Consciousness and Cognition, 18(1), 176-186.

Moore, D. L., \& Norris, F. H. (2005). Empirical investigation of the conflict and flexibility models of bisexuality. Journal of Bisexuality, 5(1), 5-25.

Mumford, M. D., Baughman, W. A., Threlfall, K. V., Supinski, E. P., \& Costanza, D. P. (1996). Process-based measures of creative problem-solving skills: I. Problem construction. Creativity Research Journal, 9(1), 63-76.

Mumford, M. D., Hester, K., \& Robledo, I. (2012). Methods in creativity research: Multiple approaches, multiple levels. In Handbook of organizational creativity (pp. 39-65). Cambridge, MA: Academic Press.

Nijstad, B. A., De Dreu, C. K., Rietzschel, E. F., \& Baas, M. (2010). The dual pathway to creativity model: Creative ideation as a function of flexibility and persistence. European Review of Social Psychology, 21(1), 34-77. 
Noor, A. M., Chee, C. S., \& Ahmad, A. (2013). Is there a gay advantage in creativity? International Journal of Psychological Studies, 5(2), 32-38.

Palm, K. M., \& Follette, V. M. (2011). The roles of cognitive flexibility and experiential avoidance in explaining psychological distress in survivors of interpersonal victimization. Journal of Psychopathology and Behavioral Assessment, 33(1), 7986.

Parker, S. K. (1998). Enhancing role breadth self-efficacy: the roles of job enrichment and other organizational interventions. Journal of Applied Psychology, 83(6), 835.

Pollitt, A. M., Brimhall, A. L., Brewster, M. E., \& Ross, L. E. (2018). Improving the field of LGBTQ psychology: Strategies for amplifying bisexuality research. Psychology of Sexual Orientation and Gender Diversity, 5(2), 129-131.

Popova, M. (2018). Inactionable/unspeakable: Bisexuality in the workplace. Journal of Bisexuality, 18(1), 54-66.

Powers, B. (1996). The impact of gay, lesbian, and bisexual workplace issues on productivity. Journal of Gay \& Lesbian Social Services, 4(4), 79-90.

Preacher, K. J., Rucker, D. D., \& Hayes, A. F. (2007). Addressing moderated mediation hypotheses: Theory, methods, and prescriptions. Multivariate Behavioral Research, 42(1), 185-227.

Ragins, B. R. (2008). Disclosure disconnects: Antecedents and consequences of disclosing invisible stigmas across work and life domains. Academy of Management Review, 33(1), 194-215. http://www.jstor.org/stable/20159383

Robinson, A., Brown, B. L., Sleight, R., \& Thomas, K. M. (2017). LGBTQ experiences in healthcare: How sexual identity matters. Don't trust the B: Bisexual stigma in 
modern organizations. Symposium to be conducted at the annual conference of the Society for Industrial Organizational Psychology, Orlando, FL., In D. F. Arena, \& K. P. Jones (Eds.).

Rodebaugh, T. L., Woods, C. M., \& Heimberg, R. G. (2007). The reverse of social anxiety is not always the opposite: The reverse-scored items of the Social Interaction Anxiety Scale do not belong. Behavior Therapy, 38(2), 192-206.

Roothman, B., Kirsten, D. K., \& Wissing, M. P. (2003). Gender differences in aspects of psychological well-being. South African Journal of Psychology, 33(4), 212-218.

Schoenfeldt, L. F., \& Jansen, K. J. (1997). Methodological requirements for studying creativity in organizations. The Journal of Creative Behavior, 31(1), 73-90.

Schriesheim, C. A., Eisenbach, R. J., \& Hill, K. D. (1991). The effect of negation and polar opposite item reversals on questionnaire reliability and validity: An experimental investigation. Educational and Psychological Measurement, 51(1), 67-78.

See, H., \& Hunt, R. (2011). Bisexuality and identity: The double-edged sword: Stonewall research into bisexual experience. Journal of Bisexuality, 11(2-3), 290-299.

Seligman, M. E. (1990). Learned optimism: How to change your mind and life. New York, New York, US: Simon \& Schuster.

Shalley, C. E., \& Gilson, L. L. (2004). What leaders need to know: A review of social and contextual factors that can foster or hinder creativity. The Leadership Quarterly, 15(1), 33-53.

Shalley, C. E., Zhou, J., \& Oldham, G. R. (2004). The effects of personal and contextual characteristics on creativity: Where should we go from here? Journal of 
Management, 30(6), 933-958.

Shrout, P. E., \& Bolger, N. (2002). Mediation in experimental and nonexperimental studies: New procedures and recommendations. Psychological Methods, 7(4), $422-442$.

Sirois, F. M., Kitner, R., \& Hirsch, J. K. (2015). Self-compassion, affect, and healthpromoting behaviors. Health Psychology, 34(6), 661-670.

Sosik, J. J., Kahai, S. S., \& Avolio, B. J. (1998). Transformational leadership and dimensions of creativity: Motivating idea generation in computer-mediated groups. Creativity Research Journal, 11(2), 111-121.

Steffens, N. K., Gocłowska, M. A., Cruwys, T., \& Galinsky, A. D. (2016). How multiple social identities are related to creativity. Personality and Social Psychology Bulletin, 42(2), 188-203.

Stoltzfus, G., Nibbelink, B. L., Vredenburg, D., \& Hyrum, E. (2011). Gender, gender role, and creativity. Social Behavior and Personality: An International Journal, $39(3), 425-432$.

Swain, S. D., Weathers, D., \& Niedrich, R. W. (2008). Assessing three sources of misresponse to reversed Likert items. Journal of Marketing Research, 45(1), 116131.

Tadmor, C. T., Galinsky, A. D., \& Maddux, W. W. (2012). Getting the most out of living abroad: Biculturalism and integrative complexity as key drivers of creative and professional success. Journal of Personality and Social Psychology, 103(3), 520542.

Terry, M. L., \& Leary, M. R. (2011). Self-compassion, self-regulation, and health. Self 
and Identity, 10(3), 352-362.

Tierney, P., \& Farmer, S. M. (2002). Creative self-efficacy: Its potential antecedents and relationship to creative performance. Academy of Management Journal, 45(6), 1137-1148.

Tierney, P., Farmer, S. M., \& Graen, G. B. (1999). An examination of leadership and employee creativity: The relevance of traits and relationships. Personnel Psychology, 52(3), 591-620.

Toossi, M. (2015). Labor force projections to 2024: The labor force is growing, but slowly. Monthly Lab. Rev., 138, 1.

Turner, V. (1967). Betwixt-and-between: The liminal period in rites de passage. In The forest of symbols: Aspects of Ndembu ritual (pp. 93-111). Cornell University Press.

Van der Heijden, B. I., \& Nijhof, A. H. (2004). The value of subjectivity: Problems and prospects for 360-degree appraisal systems. The International Journal of Human Resource Management, 15(3), 493-511.

Zampetakis, L. A., Bouranta, N., \& Moustakis, V. S. (2010). On the relationship between individual creativity and time management. Thinking Skills and Creativity, 5(1), $23-32$.

Zhang, X., \& Bartol, K. M. (2010). Linking empowering leadership and employee creativity: The influence of psychological empowerment, intrinsic motivation, and creative process engagement. Academy of Management Journal, 53(1), 107-128.

Zhou, J., \& George, J. M. (2001). When job dissatisfaction leads to creativity: Encouraging the expression of voice. Academy of Management Journal, 44(4), 
682-696.

Zhou, J., \& Hoever, I. J. (2014). Research on workplace creativity: A review and redirection. Annual Review of Organizational Psychology and Organizational Behavior, 1(1), 333-359.

Zhou, Q., Hirst, G., \& Shipton, H. (2012). Promoting creativity at work: The role of problem-solving demand. Applied Psychology, 61(1), 56-80.

Zinik, G. (1985). Identity conflict or adaptive flexibility? Bisexuality reconsidered. Journal of Homosexuality, 11(1-2), 7-20. 


\section{Appendix A}

Survey Measures

Cognitive Flexibility Scale (CFS; adapted from Martin \& Rubin, 1995).

Please rate the extent to which you agree with each of the following statements.

1=Agree not at all, $2=$ Agree not very much, $3=$ Somewhat Agree, $4=$ Moderately Agree, $5=$ Agree, $6=$ Strongly agree, $7=$ Completely agree

1. I can communicate an idea in many different ways.

2. I avoid new and unusual situations. (R)

3. I am willing to work at creative solutions to problems.

4. In any given situation, I am able to act appropriately.

5. I have many possible ways of behaving in any given situation.

6. I am willing to listen and consider alternatives for handling a problem.

7. I have the self-confidence necessary to try different ways of behaving.

Supervisor Support Scale (adapted from House \& Wells' Social Support Scale, 1978).

Please rate the extent to which you agree with each of the following statements.

1=Agree not at all, 2=Agree not very much, $3=$ Somewhat Agree, 4=Moderately Agree, $5=$ Agree, $6=$ Strongly agree, $7=$ Completely agree

1. My supervisor listens to my work-related problems.

2. My supervisor shows concern towards my job-related problems.

3. My supervisor gives me aid in dealing with my work-related problems.

4. My supervisor gives me tangible assistance to deal with my work-related stress.

5. My supervisor gives me sound advice about problems encountered on the job.

6. My supervisor gives me useful suggestions in order to get through difficult times.

7. My supervisor helps me manage conflicts with my coworkers.

8. My supervisor helps me fit in at work.

Self-report ratings of creativity (adapted from J. Zhou \& George, 2001).

Please rate the extent to which you agree with each of the following statements regarding your creative performance at work.

1=Agree not at all, $2=$ Agree not very much, $3=$ Somewhat Agree, $4=$ Moderately Agree, $5=$ Agree, $6=$ Strongly agree, $7=$ Completely agree

1. I suggest new ways to achieve goals or objectives

2. I come up with new and practical ideas to improve performance 
3. I search out new technologies, processes, techniques, and/or product ideas

4. I suggest new ways to increase quality

5. I am a good source of creative ideas

6. I am not afraid to take risks

7. I promote and champions ideas to others

8. I exhibit creativity on the job when given the opportunity to

9. I develop adequate plans and schedules for the implementation of new ideas

10. I often have new and innovative ideas

11. I come up with creative solutions to problems

12. I often have a fresh approach to problems

13. I suggest new ways of performing work tasks

\section{Employee Demographics.}

Please provide the following information about yourself.

What is your age?

What is your gender?

Female

Male

Non-Binary

Genderqueer

MTF Transgender

FTM Transgender

Agender

Other

What race/ethnicity do you identify with?

White/Non-Hispanic

African American/Black

Hispanic/Latino

Asian

Native American/Alaskan Native

Native Hawaiian/Pacific Islander

Indian/South Asian

Middle Eastern

Biracial/Multiracial

Other

What sexual orientation do you most closely identify with? Straight/Heterosexual

Gay/Lesbian

Bisexual

Asexual 
Queer

Polyamorous

Other

Highest level of education received:

Some High School

High school or GED

_ Some college

_ Vocational degree

Bachelor's Degree

Master's Degree

_ $\mathrm{PhD} / \mathrm{MD}$ or other terminal degree

Have you ever been in a public relationship (that other people knew about) with someone who identifies as the same gender as you?

Y Yes

- No

Have you ever been in a public relationship (that other people knew about) with someone who identifies as a different gender than you?

Yes

No 


\section{Appendix B}

Additional Measures of Creative Performance

For publication purposes, I plan to collect five additional measures of creativity.

\section{Supervisor/coworker ratings of creativity (J. Zhou \& George, 2001)}

Participants will be asked to nominate a supervisor or a coworker to rate their creative performance.

Please rate the extent to which you agree with each of the following statements regarding this employee's creative performance at work.

1=Agree not at all, 2=Agree not very much, 3=Somewhat Agree, 4=Moderately Agree, 5=Agree, 6=Strongly agree, $7=$ Completely agree

1. Suggests new ways to achieve goals or objectives

2. Comes up with new and practical ideas to improve performance

3. Searches out new technologies, processes, techniques, and/or product ideas

4. Suggests new ways to increase quality

5. Is a good source of creative ideas

6. Is not afraid to take risks

7. Promotes and champions ideas to others

8. Exhibits creativity on the job when given the opportunity to

9. Develops adequate plans and schedules for the implementation of new ideas

10. Often has new and innovative ideas

11. Comes up with creative solutions to problems

12. Often has a fresh approach to problems

13. Suggests new ways of performing work tasks

\section{Alternative Uses Task (AUT; Guilford, 1967)}

1. You have 2 minutes to think of as many creative uses as you can for a brick. Please be as creative as possible.

\section{Name Generation Task}

You will be given a category and asked to provide as many examples that fit within the category in 1 minute. All answers that fit the category will be given 1 point, but "creative" answers will be given 2 points. Off-topic answers will not earn points. Try to earn as many points as possible. 
For example, if you were given the category "rocks," acceptable answers might include "boulder, pebble, sedimentary" and creative answers might include "Hard Rock Cafe, Rock n Roll Music, Little Rock Arkansas.”

1. List as many things you can think of that are green (example)

\section{Free Response Question}

1. Think of a time you were creative at work. Please provide as much detail and information as possible.

Remote Associates Test (RAT; Mednick, 1962).

Participants scored based on the number of correct solutions.

\begin{tabular}{|l|l|l|l|}
\hline Word 1 & Word 2 & \multicolumn{1}{|c|}{ Word 3 } & Solution \\
\hline Blank & White & Lines & Paper \\
\hline Magic & Red & Floor & Carpet \\
\hline Thread & Pine & Magnetic & Needle \\
\hline Stop & Petty & Sneak & Thief \\
\hline Envy & Golf & Beans & Green \\
\hline Chocolate & Fortune & Tin & Cookie \\
\hline Barrel & Root & Belly & Beer \\
\hline Broken & Clear & Eye & Glass \\
\hline Gun & Salt & Fall & Water \\
\hline Chamber & Staff & Box & Music \\
\hline Sharp & Blue & Cake & Cheese \\
\hline Hall & Car & Swimming & Pool \\
\hline Square & Cardboard & Lunch & Box \\
\hline High & Book & Foot & Note \\
\hline Gold & Stool & Tender & Bar \\
\hline & & & \\
\hline
\end{tabular}




\section{Supervisor/Coworker Demographics}

When collecting supervisor ratings of creativity, I will also collect supervisor demographics.

What is your age?

What is your gender?

Female

Male

Non-Binary

Genderqueer

MTF Transgender

FTM Transgender

Agender

Other

What race/ethnicity do you identify with?

White/Non-Hispanic

African American/Black

Hispanic/Latino

Asian

Native American/Alaskan Native

Native Hawaiian/Pacific Islander

Indian/South Asian

Middle Eastern

Biracial/Multiracial

Other

What sexual orientation do you most closely identify with?

Straight/Heterosexual

Gay/Lesbian

Bisexual

Asexual

Queer

Polyamorous

Other 


\section{Appendix C}

Final Models with Coefficients

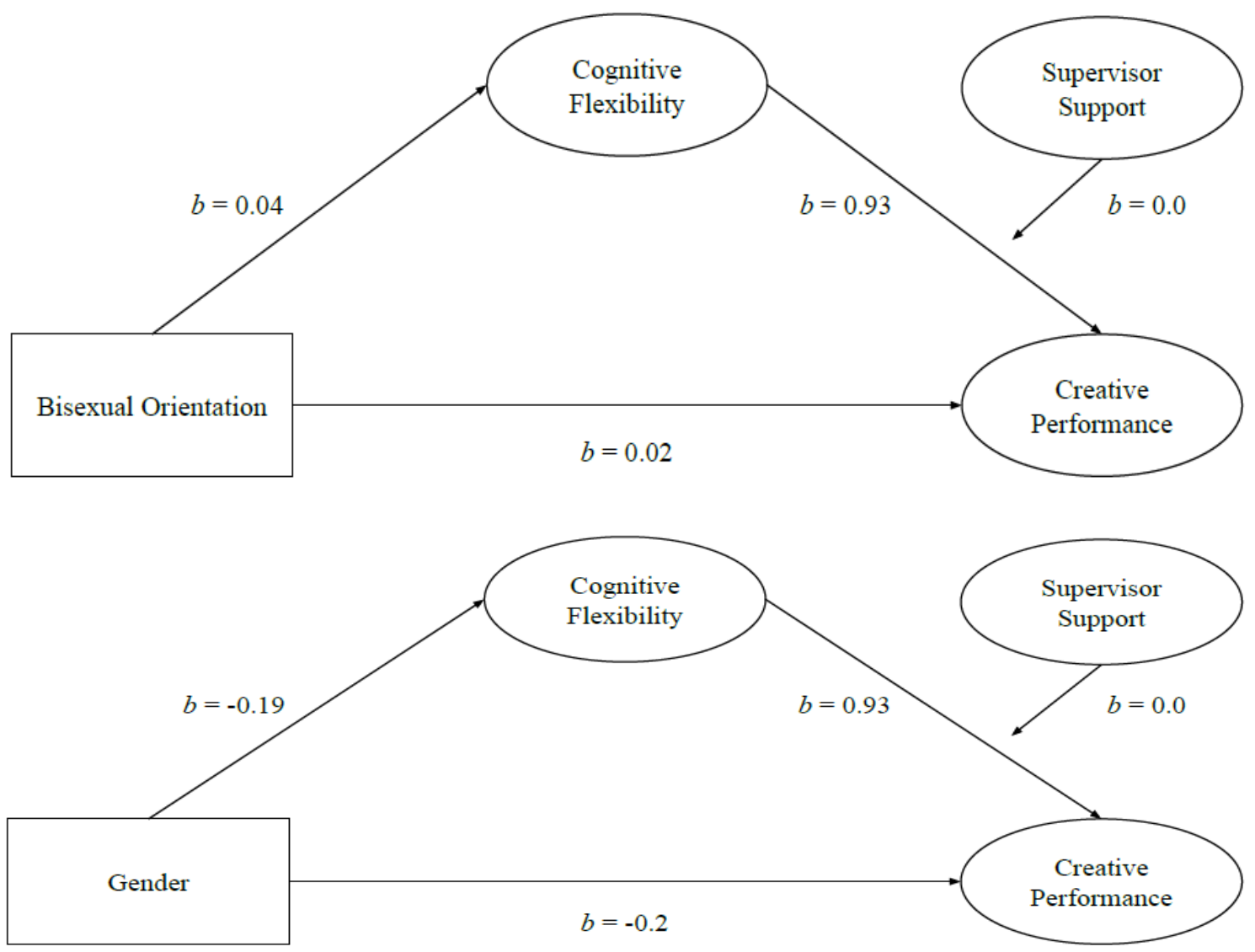

